\title{
American depositary receipt: uma estratégia de controle da volatilidade na BM\&FBovespa
}

\author{
American depositary receipt: a strategy for \\ volatility control in BM\&FBovespa
}

\section{Daniel Roberto Guimarães Pereira ${ }^{[a]}$, Lucilaine Maria Pascucci ${ }^{[b]}$, Wesley Vieira da Silva ${ }^{[c]}$}

[a] Doutorando em Administração do Programa de Pós-Graduação da Pontifícia Universidade Católica do Paraná (PPAD/ PUCPR), professor assistente III da Pontifícia Universidade Católica do Paraná (PUCPR), Curitiba, PR - Brasil, e-mail: daniel.pereira@pucpr.br

[b] Doutoranda em Administração do Programa de Pós-Graduação da Pontifica Universidade Católica do Paraná (PPAD/PUCPR), gerente de planejamento da Associação Paranaense de Cultura, Curitiba, PR - Brasil, e-mail: lucilaine.pascucci@pucpr.br

[c] Doutor em Administração, professor titular da Pontifícia Universidade Católica do Paraná (PUCPR), Curitiba, PR - Brasil, e-mail: wesley.vieira@pucpr.br

\section{Resumo}

Esta pesquisa investiga a existência de diferenças estatisticamente significativas nas volatilidades dos preços das ações cotadas na BM\&FBovespa após o lançamento de american depositary receipt (ADR) na New York Stock Exchange (NYSE). Foram analisadas as empresas Braskem, Gerdau, Petrobras, CSN e Vale durante o período de janeiro de 1994 até dezembro de 2007, com uma janela de estimação de quatro meses. Optou-se por esse período em função da estabilidade monetária no Brasil após a implantação do Plano Real. Como critério de escolha das organizações, utilizou-se a importância atribuída pelo mercado acionário e os setores da economia dos quais participam, permitindo-se uma melhor comparação dos resultados. Fez-se uso da estimativa e análise do risco sistemático (coeficiente Beta) como medida de volatilidade. Considerou-se como hipótese nula a ser testada a não existência de diferenças estatisticamente significantes entre as volatilidades dos ativos antes e após a data do evento. Os resultados evidenciam para - sendo exceção feita a CSN - a aceitação da hipótese nula, indicando não haver diferenças estatisticamente significativas nos padrões de volatilidade das ações negociadas na BM\&FBovespa antes e após o lançamento de ADRs na NYSE.

Palavras-chave: American depositary receipt. Volatilidade. Mercado de ações.

\begin{abstract}
This research aims to analyze whether there were significant volatility differences on the BMEFBovespa stocks prices after the initial american depositary receipt (ADR) launch on the New York Stock Exchange. We analyzed five important companies in the Brazilian stock market: Braskem, Gerdau, Petrobras, CSN and Vale.
\end{abstract}


The study took place between January 1994 and December 2007 with a four-month window in each case. After 1994 the inflation in Brazil was under control and we chose this period due to the stability of the Brazilian currency. To verify significant volatility differences we used Beta analyses. The null hypothesis was defined as equality of volatilities before and after the analyzed event. Except for the CSN case, the null hypothesis was not rejected. This event study allowed us to learn that there are no significant differences in the patterns of volatility in BMEFBovespa stock market prices before and after an initial launch of American depositary receipts on the New York Stock Exchange.

Keywords: American depositary receipt. Volatility. Stock market.

\section{Introdução}

Entre as diversas linhas de pesquisa da área de finanças, a pesquisa em mercado de capitais possui uma posição de destaque. A importância dessa linha de pesquisa deve-se ao fato de que os mercados de capitais representam ambientes em que as práticas e hipóteses financeiras podem ser testadas (BRUNI, 2002).

O grupo dos vinte países mais desenvolvidos do mundo experimentou nos últimos anos um forte movimento de capitais entre as suas bolsas de valores. A internacionalização dos seus mercados muito contribuiu para a melhora do nível de gestão das empresas, a captação de novos recursos e o controle do risco diversificável, apesar do claro aumento do risco sistemático. Nos últimos cinco anos, observouse um forte retorno das organizações brasileiras ao mercado de capitais, por meio de ofertas públicas iniciais ou novas subscrições de ações, momentaneamente reduzido em decorrência da crise financeira mundial iniciada no segundo semestre de 2008.

O mercado de capitais brasileiro, nos últimos anos, recebeu especial atenção do cenário internacional e se manteve em posição de destaque mesmo com o rigor da atual crise financeira mundial. $\mathrm{O}$ declínio da economia mundial em relação ao crescimento das economias dos países emergentes, com especial destaque para China, Rússia, Índia e Brasil, contribui para aumentar o interesse do empresário brasileiro pelos recursos disponíveis para investimento em ações.

A recente melhora na classificação de risco do Brasil, passando para grau de investimento seguro, mesmo quando considerado o cenário da crise mundial atual, aumenta a disposição dos investidores internacionais em direcionar novos recursos para a Bolsa de Valores de São Paulo ou para as empresas brasileiras listadas na Bolsa de Nova Iorque por meio de american depositary receipts (ADRs) (ANDREZZO; LIMA, 2009).
O lançamento de um programa de ADR na New York Stock Exchange (NYES) tem se mostrado um bom caminho para as empresas com ações negociadas na BM\&FBovespa ampliarem as suas capacidades de captação de novos recursos. Além de permitir às empresas brasileiras acesso ao maior $\mathrm{e}$ mais sofisticado mercado de capitais do mundo, um programa de ADR na NYES oferece maior liquidez às negociações das ações, contribui para melhorar a visibilidade internacional da empresa, melhorar a percepção do investidor quanto ao risco do investimento e, num estágio mais avançado de disclosure e adaptação, permite captar recursos a taxas menores que as praticadas no mercado interno (BOTOSAN, 2000).

Por meio da análise do estudo de evento, em que o pesquisador busca saber se determinado fato interfere ou não no desempenho de uma variável ou em um padrão de comportamento (SOARES; ROSTAGNO; SOARES, 2002), este trabalho busca investigar o efeito da negociação de ADRs na Bolsa de Valores de Nova Iorque na volatilidade das ações na BM\&FBovespa. Busca, assim, testar um dos pressupostos do lançamento de um programa de ADR na NYES que considera haver relação entre o risco doméstico das ações e a negociação de ADRs na NYES (DAMODARAN, 2003).

Num primeiro momento são apresentadas as considerações sobre estudos de evento, suas aplicações e operacionalização, bem como uma análise sobre os ADRs e suas relações com a volatilidade das ações no mercado brasileiro. $\mathrm{Na}$ sequência, são apresentados os procedimentos metodológicos e um estudo comparativo de casos com cinco importantes empresas dos setores de extração e transformação de minérios. A escolha das empresas decorre da relevante participação destas - peso-na composição do Ibovespa, principal índice da BM\&FBovespa. Os dados analisados foram extraídos do banco de dados Economática Softwares para Investimentos 
LTDA. Por fim, tem-se a apresentação e discussão dos resultados do estudo e a conclusão a partir dos resultados obtidos.

\section{Suporte teórico-empírico}

Nesta seção são apresentados os motivos que levaram os pesquisadores a optarem pela técnica do estudo de evento, oferecendo ao leitor uma melhor compreensão dessa estratégia de análise dos dados pesquisados. Apresenta-se, também, uma breve explicação do mercado de ADR e o efeito da volatilidade no mercado de ações.

\section{Estudos de eventos}

A utilização do estudo de evento na área de finanças remonta ao início do século passado e a um trabalho de Dolley (1933) que analisou os efeitos nos preços nos dias próximos aos anúncios de 95 desdobramentos de ações ocorridos entre 1921 e 1931 (MACKINLAY, 1997). Com o passar dos anos houve uma evolução natural nessa metodologia. Tornou-se sofisticada e amplamente utilizada em finanças quando o pesquisador busca analisar o efeito da divulgação de informações específicas de determinadas empresas sobre o preço de suas ações. É, também, uma metodologia muito utilizada em testes de eficiência de mercado e, especificamente em finanças, na aferição da eficiência informacional do mercado em sua forma semiforte. O estudo de evento pode ser utilizado a partir da ocorrência de eventos importantes - geralmente informações divulgadas no mercado - que tenham impacto significativo nas expectativas de investidores e, portanto, no preço das ações.

Camargo e Barbosa (2003) destacam como eventos desse tipo a subscrição de ações, a emissão de títulos de dívida como debêntures, o lançamento de recibos em outros mercados (DRs), bonificações, pagamento de dividendos, fusões e aquisições, entre outros. Para Brown e Warner (1980) a maior contribuição do estudo de evento é a possibilidade de se avaliar a extensão em que a variação dos preços de títulos em dias próximos a eventos é anormal, quando comparados a períodos considerados normais. Ainda segundo os mesmos autores, a racionalidade do mercado faz com que os efeitos do evento reflitam imediatamente nos preços dos títulos influenciados por determinada informação. Os procedimentos de um estudo de evento são descritos por Campbell, Lo e Mackinlay (1997) como demonstrado a partir da Figura 1, apresentada na sequência:

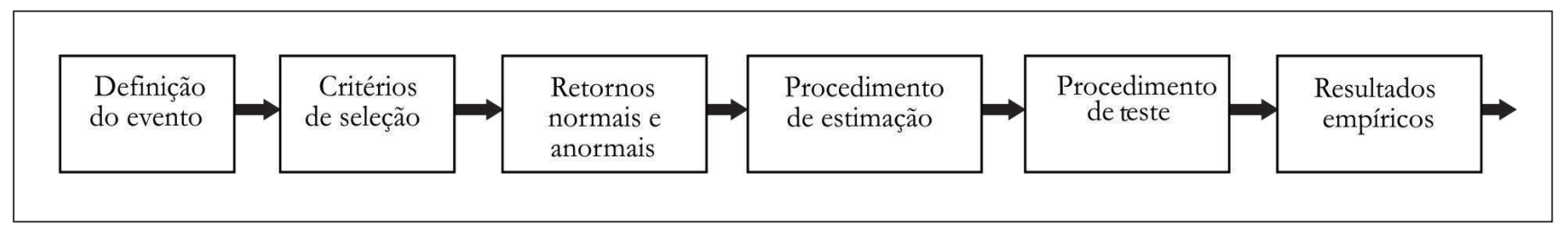

Figura 1 - Procedimento de um estudo de eventos Fonte: CAMPBELL; LO; MACKINLAY, 1997.

$\mathrm{Na}$ definição do evento, escolhe-se o evento de interesse, identifica-se sua data de ocorrência e o período durante o qual os preços dos títulos das firmas envolvidas nesse evento serão examinados (CAMARGOS; BARBOSA, 2003).

A definição do número de dias antes e depois da "data zero", ou seja, da data de ocorrência do evento, dependerá do pesquisador. Todavia, é importante que cubra períodos considerados relevantes para a verificação de anormalidades no comportamento dos preços. A definição dos critérios de seleção refere-se, especificamente, à escolha da base de dados a ser utilizada, à seleção do setor econômico e às empresas afetadas pelo evento em estudo. Retornos normais são os retornos esperados sem a condição de que o evento ocorra. Já o retorno anormal é definido como o retorno observado ex-post de um título menos o retorno normal da firma na janela de evento (período em que é analisado o evento).

Nos procedimentos de estimação, define-se a janela de estimação a ser utilizada para cálculo dos parâmetros do modelo de determinação de retornos normais escolhido. É importante ressaltar que essa janela não deve sobrepor-se à janela do evento, de 
forma a não influenciar os parâmetros do modelo de determinação de retornos normais.

Quando dos procedimentos de teste, é delineada a estrutura de teste para que os retornos anormais possam ser calculados. Também se define a hipótese nula e as técnicas a serem utilizadas para agregação dos retornos anormais das firmas individualmente.

$\mathrm{Na}$ apresentação dos resultados, deve-se atentar para os outliers e suas possíveis influências nos resultados. A partir dos resultados encontrados, as hipóteses são testadas e são descritos os resultados obtidos (SOARES; ROSTAGNO; SOARES, 2002).

\section{American depositary receipts (ADRs) e volatilidade}

Um american depositary receipt é um recibo de depósito de títulos e valores mobiliários de empresas não americanas, negociável no mercado norte-americano, seja em bolsa de valores ou em mercado de balcão organizado, dependendo do tipo de programa (LIMA, 2005). Ainda de acordo com o mesmo autor, as ações da companhia emissora são custodiadas no país de origem, por meio de um Banco juridicamente competente (banco custodiante), que presta serviço de custódia dos títulos e valores. Nos Estados Unidos haverá uma "instituição depositária" que emitirá ou fará o cancelamento dos recibos, com base nos valores custodiados no país de origem.

Um dos principais problemas que podem ocorrer a um investidor no momento de compra de um ADR é o risco de liquidez. O risco de liquidez é a provável perda de negociabilidade do título no mercado, o que equivale a não haver compradores no mercado para um recibo negociável de determinada empresa, após a sua passagem pelo mercado primário (HAIL, 2002).

Para Brigham e Westom (2000), um ponto a ser considerado é a possibilidade de o investidor ser afetado pelo risco de mercado, que é caracterizado como a incerteza a respeito dos resultados de um investimento ou carteira de investimento e que geralmente está associado a mudanças futuras nas condições de mercado.

Matsumoto (1995) considera o lançamento de um programa de ADR algo positivo na medida em que permite a expansão do market share por meio do alargamento e maior diversificação da exposição a investidores com grande potencial de liquidez, o qual pode aumentar ou estabilizar o preço da ação; melhorar a visibilidade e a imagem dos produtos, serviços e instrumentos financeiros da companhia realçados fora do seu mercado de origem; oferecer menor custo de capital quando comparado com as despesas e comissões cobradas no mercado doméstico e os ganhos em escala.

Muitas empresas latino-americanas e europeias possuem recibos de depósitos americanos (american depository receipts - ADR) listados no mercado americano. Esses papéis garantem direitos equivalentes aos obtidos quando da compra de ações no país de origem. Teoricamente deveriam ser negociados a um preço consistente com os das ações nesses países e oferecerem o mesmo nível de risco (volatilidade). O que os torna potencialmente mais arriscados é que ADRs nem sempre são diretamente comparáveis às ações ordinárias negociadas em seus países de origem.

Um ADR, por exemplo, pode equivaler a 20 ações da empresa em seu mercado doméstico. Além disso, a conversão de ADRs em ações locais pode ser dispendiosa e demorada. Em alguns casos também podem existir diferenças de direitos a voto. Apesar dessas restrições, seria de se esperar que o preço de um ADR acompanhasse de perto o preço das ações no seu mercado de origem, embora com uma equivalência cambial, já que os ADRs são denominadas em dólar (DAMODARAN, 2003).

Em um estudo realizado em 2000, Kin, Szakmary e Mathur examinaram a relação entre os ADRs e as ações locais e concluíram que cerca de $60 \%$ a $70 \%$ da variação de seus preços pode ser explicada pelos movimentos nos preços das ações subjacentes e que os ADRs reagem exageradamente ao mercado dos EUA e reagem de menos às variações nas taxas de câmbio. Concluíram, também, que os investidores não podem tirar vantagem dos erros de precificação de ADRs porque a convergência de preços não ocorre com rapidez nem de forma previsível. Damodaran (2003) destaca, ainda, que um maior horizonte de tempo pode ser capaz de oferecer ganhos com diferenças significativas de precificação.

Um ponto sempre presente no processo de decisão do investidor é a volatilidade associada ao ativo objeto. A busca da compreensão dos motivos que promovem o aumento ou a diminuição da volatilidade das ações está sempre presente nos estudos acadêmicos. Nos últimos anos, vários estudos têm constatado uma relação entre as mudanças nas volatilidades dos mercados e os retornos futuros. 
Um estudo publicado por Haugen, Talmor e Torous (1991) verificou que os aumentos da volatilidade do mercado causam uma queda imediata nos preços das ações, e que esses retornos aumentam nos períodos subsequentes. Analisando a volatilidade diária dos preços entre 1897 e 1988, os autores buscaram identificar períodos de tempo nos quais a volatilidade aumentou ou diminuiu de forma significativa em relação aos períodos anteriores. Os autores observaram que os preços das ações caem à medida que a volatilidade aumenta e que voltam a subir nas quatro semanas seguintes. No caso de quedas de volatilidade os preços das ações sobem no momento da mudança e continuam a subir nas semanas seguintes, embora em ritmos mais lento.

A estratégia de comprar ações após um aumento da volatilidade não significa, necessariamente, aumento na probabilidade de melhores retornos. $\mathrm{O}$ aumento nos retornos nas semanas que se seguem a um aumento da volatilidade pode apenas refletir o fato de que os investimentos em ações se tornaram mais arriscados. Por outro lado, investidores que acreditam ser o aumento da volatilidade temporário e que irá reverter a níveis normais podem obter retornos positivos ao adotarem a estratégia de comprar ações após um aumento da volatilidade dos mercados de capitais (DAMODARAN, 2003).

A compreensão da volatilidade dos mercados de ações deve sempre orientar a tomada de decisão dos investidores. A busca pela compreensão dessa volatilidade tem motivado os pesquisadores das principais universidades do mundo a desenvolverem modelos capazes de captar com maior precisão esse fenômeno. Os motivos que provocam a volatilidade dos mercados de ações são diversos e ainda não se chegou a um modelo capaz de prever os movimentos futuros com precisão. Ao analisar o efeito do lançamento de um programa de ADR na NYSE na volatilidade das ações no mercado brasileiro, este artigo oferece a sua contribuição nessa importante busca para a diminuição do risco não sistemático.

\section{Metodologia}

\section{Delineamento da pesquisa}

$\mathrm{Na}$ visão de Gil (2007), o delineamento da pesquisa diz respeito à forma como se planeja uma pesquisa em sua dimensão mais ampla. É nesse instante que o pesquisador estabelece os meios técnicos da investigação, prevendo os instrumentos e procedimentos necessários para a coleta dos dados.

Este trabalho utiliza-se do método hipotético dedutivo, proposto por Karl Popper no século $\mathrm{XX}$, que tem como base colocar os conhecimentos já existentes em questionamento, com o objetivo de surgirem novos conhecimentos.

Notadamente que um trabalho de pesquisa será considerado como científico caso venha a utilizar um método. Este, por sua vez, procura traduzir o modelo utilizado de forma minuciosa ou pelo menos suficiente o bastante para que o trabalho tenha condições de ser reproduzido em outras circunstâncias ou sobre a mesma condição proposta. Ao caracterizar esta pesquisa em função do método que será aplicado, tal pesquisa utiliza-se do método estatístico, que se apoia em informações quantitativas, buscando explicações de causa e efeito.

Quanto à natureza do trabalho, essa pesquisa pode ser caracterizada como uma pesquisa aplicada, pois, tal como afirma Jung (2004), tem finalidades imediatas, utilizando-se de conhecimentos advindos de pesquisa básica ou tecnológica.

Quanto ao objetivo da pesquisa, a proposta de trabalho pode ser classificada como uma pesquisa descritiva, uma vez que o objetivo do estudo, segundo Jung (2004, p. 152), aponta para "a identificação, registro e análise das características, fatores ou variáveis que se relacionam com o fenômeno ou processo".

Este trabalho ainda pode ser caracterizado levando em conta a aquisição de referências bibliográficas. Nesse sentido, o referido trabalho pode ser visto como uma pesquisa bibliográfica que objetiva conhecer as diferentes contribuições científicas sobre riscos do papel avaliado (ADRs).

A pesquisa pode ainda ser caracterizada em função do tempo de coleta e aplicação (dimensão do tempo). Nesse caso, o referido trabalho pode ser visto como um estudo longitudinal, uma vez que os dados coletados descrevem tendências e eventos ao longo do tempo (HAIR Jr. et al., 2005).

Em relação aos procedimentos técnicos utilizados, este trabalho pode ser classificado como uma pesquisa com delineamento ex-post facto. $\mathrm{Na}$ visão de Gil (2002), a classificação desse trabalho se enquadra com esse tipo de pesquisa, pois se refere aos experimentos realizados após a ocorrência dos fatos e, sendo assim, o pesquisador não tem controle sobre as variáveis analisadas. 


\section{Coleta dos dados}

Todos os dados foram obtidos por meio do Banco de Dados Economática Softwares para Investimentos LTDA, disponível no Programa de Pós-Graduação em Administração da Pontifícia Universidade Católica do Paraná. A coleta de dados ocorreu na terceira semana de junho de 2008, sendo os períodos coletados apresentados no item anterior.

\section{Tratamento dos dados}

O presente estudo definiu como evento a ser analisado o lançamento de ADRs pelas empresas Braskem, Gerdau, Petrobras, CSN e Vale na Bolsa de Valores de Nova Iorque. A escolha das empresas decorre dos seus setores de atuação, extração e transformação de minérios estarem em constante destaque no cenário econômico mundial e, ainda, pela importância em termos de quantidade e valores negociados pelas empresas na BM\&FBovespa, com forte impacto no desempenho do Ibovespa, principal direcionador de desempenho médio do mercado brasileiro.

Fixou-se a janela do evento de quatro meses, sendo dois antes e dois após o lançamento de ADR na Bolsa de Valores de Nova Iorque. Todas as séries temporais analisadas partiram do mês de janeiro de 1994. A escolha da data inicial da série temporal decorre da mudança ocorrida na economia brasileira com a implantação do Plano Real naquela época, tornando o mercado brasileiro mais linear e com menores distorções inflacionárias. As séries analisadas, apesar do cenário de maior estabilidade, foram ajustadas pela inflação com base no IPCA da Fundação Getúlio Vargas. Na Figura 2, estão demonstrados os intervalos das cinco séries analisadas.

Os inícios das negociações de ADRs na Bolsa de Nova Iorque das empresas analisadas ocorreram nas datas dispostas no Quadro 1.

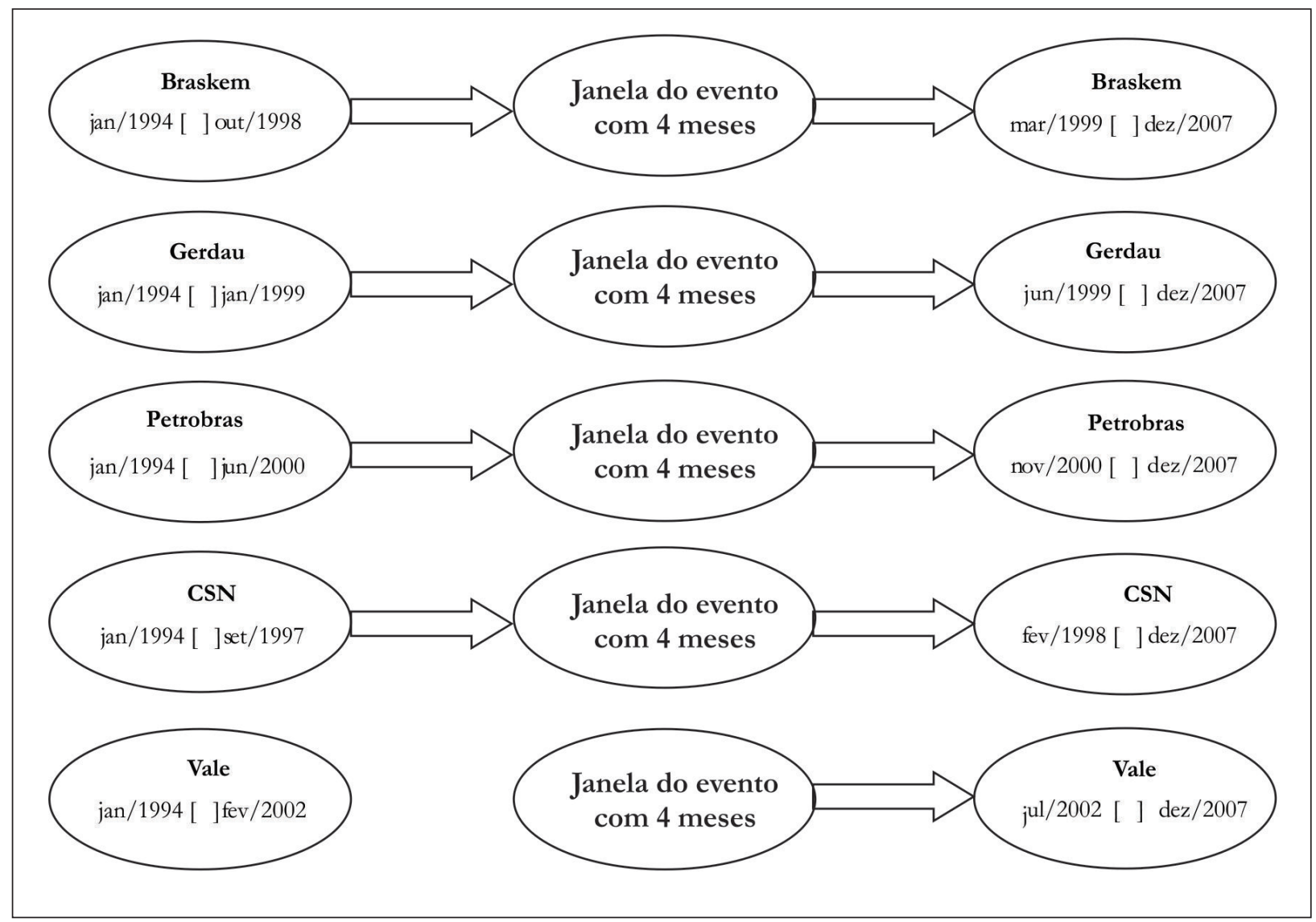

Figura 2 - Janelas dos eventos avaliados

Fonte: Elaboração dos autores. 


\begin{tabular}{llc}
\hline Empresas & Setores da economia & Início série ADR \\
\hline Braskem & Indústria química & $20 / 12 / 1998$ \\
Gerdau & Transformação de aço em produtos de aço & $10 / 03 / 1999$ \\
Petrobras & Extração de petróleo e gás & $10 / 08 / 2000$ \\
CSN & Transformação de aço em produtos de aço & $14 / 11 / 1997$ \\
Vale & Mineração de metais & $15 / 04 / 2002$ \\
\hline
\end{tabular}

Quadro 1 - Datas do início das negociações dos ADRs das empresas analisadas

Fonte: Economática Softwares para Investimentos LTDA (2008).

Após a seleção dos dados por meio do banco de dados Economática, foram calculadas para as cinco empresas analisadas as variações mensais, de janeiro de 1994 até dezembro de 2007, dos valores de fechamento das ações negociadas na BM\&FBovespa e do Ibovespa. A taxa Selic utilizada foi o valor praticado no último dia útil de cada mês. As variações mensais foram calculadas pelas diferenças entre os logaritmos neperianos do mês em análise em relação ao mês anterior.

O coeficiente beta $(\beta)$ foi adotado como retorno normal e anormal das séries, ou seja, o direcionador da volatilidade antes e depois do evento analisado. Dessa forma, para a estimativa do coeficiente beta, fez-se uso do capital asset pricing model (CAPM).

O CAPM é um modelo expectacional expresso em termos de valores esperados, em que o retorno esperado do ativo é a soma de dois fatores: a) a rentabilidade dos ativos ou aplicações sem risco, e b) o chamado prêmio de risco (TOSTÁ DE SÁ, 1999), que se refere ao retorno adicional exigido por investidores para compensar cada unidade de risco adicional por eles assumido. O coeficiente beta $(\beta)$ é usado para mensurar o risco não diversificável da empresa. É um indice que mede o grau de movimento do retorno de um ativo em resposta à mudança no retorno de mercado (DAMODARAN, 2003).

Neste estudo, o coeficiente beta foi obtido valendo-se da divisão entre a diferença do retorno esperado do ativo e o retorno livre de risco e a diferença entre o retorno médio do mercado e o retorno livre de risco. Considerou-se como retorno esperado do ativo objeto (R[E]) o desempenho individual da ação na BM\&FBovespa; como retorno médio de mercado, $\left(R_{m}\right)$, o Ibovespa; e como taxa livre de risco $(R)$, a Selic. A expressão algébrica utilizada para mensurar o coeficiente beta encontra-se descrita na sequência (Expressão 1):

Expressão 1:

$$
R[E]=R_{f}-\beta\left(R_{m}-R_{f}\right) \text { e } \beta=\frac{R[E]-R_{f}}{R_{m}-R_{f}}
$$

Após a estimativa de todos os coeficientes beta individuas, pautando-se nas séries temporais mensais, foram calculadas as estatísticas descritivas para aidentificação das medidas de tendência central.

Com as medidas descritivas mensuradas, calcularam-se as diferenças entre as médias dos coeficientes beta das séries temporais antes e após o evento, presumindo-se que as variâncias sejam equivalentes. Os cálculos buscavam responder à seguinte hipótese de pesquisa:

Em que $\mathrm{H}_{0}=$ o risco sistemático das empresas avaliadas antes do evento não difere estatisticamente do risco sistemático das empresas avaliadas após o evento.

$$
\begin{aligned}
& H_{0}: \beta_{\text {antes }}=\beta_{\text {após }} \\
& H_{1}: \beta_{\text {antes }}<\beta_{\text {após }}
\end{aligned}
$$

Segundo Pindyck e Rubinfeld (1991), hipótese estatística é uma suposição sobre o valor de algum parâmetro populacional. A comprovação ou rejeição dessa suposição pode ser obtida por meio da realização de um teste estatístico. Quando se realiza um teste de hipótese lida-se com duas hipóteses necessariamente excludentes que devem ser enunciadas da seguinte forma: 
- $\mathrm{H}_{0}$ ou hipótese nula, que deve ser construída de tal forma a ser rejeitada;

- $\mathrm{H}_{1}$ ou hipótese alternativa, aquela suposição que se quer comprovar.

O teste de hipótese lida, ainda, com a incerteza. A aceitação ou rejeição de uma hipótese estará sempre condicionada à existência de algum erro. Assim, convencionou-se definir dois tipos de erro:

- erro tipo 1 - rejeitar $\mathrm{H}_{0}$ quando ela é verdadeira;

- erro tipo2-aceitar $\mathrm{H}_{0}$ quando ela é falsa.

Rejeitando-se $\mathrm{H}_{0}$ haverá maior certeza acerca da conclusão adotada. O erro tipo 1 desempenha um papel importante na análise. A ele está associada uma probabilidade de ocorrência conhecida como nível de significância do teste estatístico. O nível de significância adotado na presente pesquisa foi de $5 \%$, isso implica que, se $\mathrm{H}_{0}$ for rejeitada, existe $5 \%$ de chance de se estar cometendo um erro.

Buscando responder às hipóteses de pesquisa, este estudo se deparou com a necessidade de realizar comparações entre as médias de duas amostras independentes. As premissas para a realização do teste de diferenças entre duas médias independentes, tal como enfoca Lapponi (1997), são as seguintes:

- as duas populações têm médias e variâncias próprias;

- são extraídas duas amostras independentes;

- a diferença das duas médias é uma nova variável aleatória, que poderá ser maior ou menor do que zero;

- a variância dessa nova variável é igual à soma das variâncias anteriores.

Considerou-se, ainda, a existência de algumas situações particulares:

- variâncias populacionais conhecidas uso de distribuição normal;

- variâncias populacionais desconhecidas e iguais - uso da distribuição t-student;

- variâncias populacionais desconhecidas e distintas - uso de distribuição t-student com fator de correção.
Para aceitação da hipótese nula $\left(\mathrm{H}_{0}\right)$, este trabalho considerou o valor da estatística t-student em relação ao valor da estatística t-student crítico unicaudal. Para valores da estatística t-student menores do que o valor t-student crítico unicaudal com 95\% de confiança, aceita-se a hipótese nula de igualdade entre os coeficientes beta médios nos períodos analisados, indicando não haver mudanças estatisticamente significativas na volatilidade das ações analisadas na BM\&FBovespa e no lançamento de ADRs na Bolsa de Valores de Nova Iorque. A estatística t-student evidencia se um conjunto de números é estatisticamente significativo maior ou menor do que outro. Tal estatística é utilizada com o objetivo de avaliar se existem diferenças entre as médias de dois conjuntos de dados e é dada pela Expressão 2, definida a seguir. Maiores detalhes sobre essa estatística consultem Freund e Simon (2000).

Expressão 2:

$$
\mathrm{t}=\frac{\overline{\mathrm{x}}_{1}-\overline{\mathrm{x}}_{2}}{\mathrm{~S} \cdot \sqrt{\frac{1}{\mathrm{n}_{1}}+\frac{1}{\mathrm{n}_{2}}}}
$$

Onde o desvio-padrão definido por S pode ser mensurado tal como se encontra na Expressão 3:

Expressão 3:

$$
\mathrm{S}^{2}=\frac{\left(\mathrm{n}_{1}-1\right) \cdot \mathrm{S}_{1}^{2}+\left(\mathrm{n}_{2}-1\right) \cdot \mathrm{S}_{2}^{2}}{\mathrm{n}_{1}+\mathrm{n}_{2}-2}
$$

Observe que na Expressão 2 as estatísticas $\overline{\mathrm{X}}_{1} \mathrm{e} \overline{\mathrm{X}}_{2}$ são as médias aritméticas dos dois conjuntos de números, $\mathrm{S}_{1}$ e $\mathrm{S}_{2}$ são as raízes quadradas das variâncias dos dois conjuntos, e $\mathrm{n}_{1}$ e $\mathrm{n}_{2}$ são os números de pontos em cada conjunto. Uma estatística t-student maior do que 1,66 indica que a variável é significativamente diferente de zero com $95 \%$ de certeza.

\section{Apresentação e análise dos resultados}

Os dados dispostos na Tabela 1 referemse às estimativas dos coeficientes beta antes $\mathrm{e}$ após a ocorrência do evento, bem como às estatísticas t-student de diferenças entre duas médias independentes. 
Tabela 1 - Estimativas das estatísticas a serem avaliadas

\begin{tabular}{|c|c|c|c|c|c|c|c|c|c|}
\hline \multirow{2}{*}{ Empresa } & \multirow{2}{*}{$\begin{array}{l}\text { Tipo } \\
\text { ação }\end{array}$} & \multirow{2}{*}{$\begin{array}{l}\text { Data início } \\
\text { série }\end{array}$} & \multicolumn{2}{|c|}{ Amostra } & \multicolumn{2}{|c|}{ Beta médio } & \multirow{2}{*}{$\begin{array}{l}\text { t-student } \\
\text { calculado }\end{array}$} & \multirow{2}{*}{$\begin{array}{l}\text { t-student } \\
\text { unicaudal }\end{array}$} & \multirow{2}{*}{ Resultado } \\
\hline & & & Antes & Após & Antes & Após & & & \\
\hline Braskem & PN & $20 / 12 / 1998$ & 38 & 87 & 1,01973 & 0,99945 & 1,05230 & 1,65734 & Aceita-se $\mathrm{H}_{0}$ \\
\hline Gerdau & PN & $10 / 03 / 1999$ & 44 & 102 & 0,99590 & 0,98470 & 0,80142 & 1,65550 & Aceita-se $\mathrm{H}_{0}$ \\
\hline Petrobras & PN & $10 / 08 / 2000$ & 78 & 86 & 0,99285 & 0,99057 & 0,25670 & 1,65431 & Aceita-se $\mathrm{H}_{0}$ \\
\hline$C S N$ & $P N$ & $14 / 11 / 1997$ & 45 & 119 & 1,05015 & 0,98311 & 2,00222 & 1,65431 & Rejeita-se $H_{0}$ \\
\hline Vale & $\mathrm{PN}$ & $15 / 04 / 2002$ & 98 & 66 & 0,99654 & 0,99129 & 0,49353 & 1,65431 & Aceita-se $\mathrm{H}_{0}$ \\
\hline
\end{tabular}

Fonte: Elaboração do autor.

Feita a exceção para a Companhia Siderúrgica Nacional (CSN), as demais empresas analisadas evidenciaram os valores para a estatística t-student calculados menores do que os valores do t-student crítico unicaudal, indicando que o evento de lançamento de ADRs na Bolsa de Valores de Nova Iorque não alterou o padrão de comportamento da volatilidade das ações das mesmas empresas na Bolsa de Valores de São Paulo.

A Figura 3 mostra o comportamento do risco sistemático para a empresa analisada antes e após a ocorrência do evento. Observe visualmente que, de fato, a volatilidade se altera ao longo do tempo após a ocorrência do evento analisado.
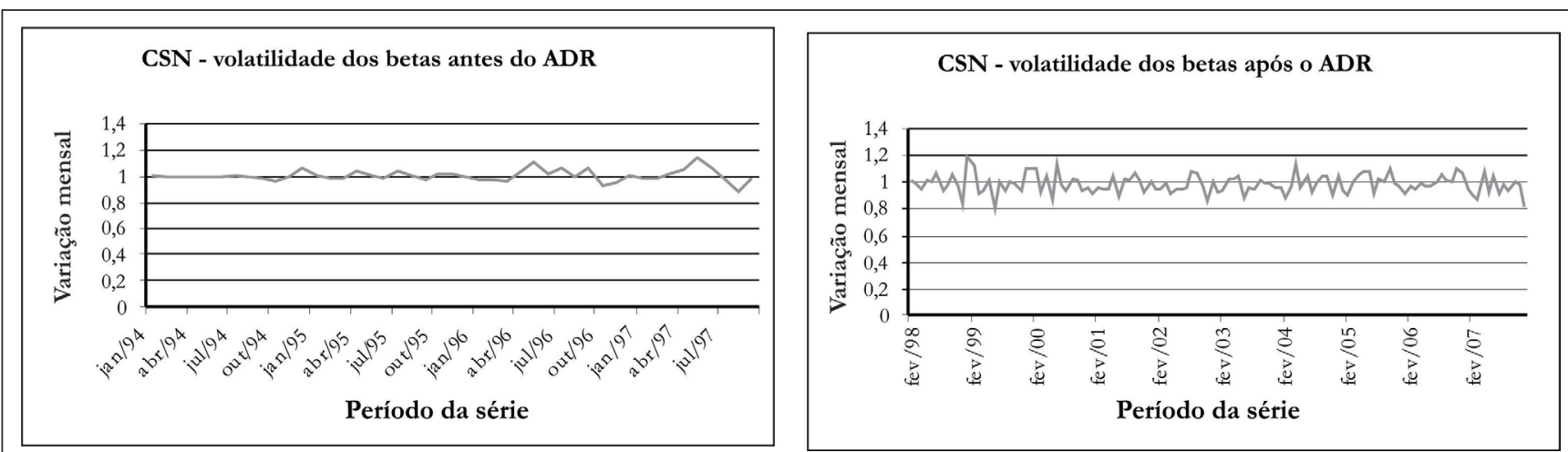

Figura 3 - Comportamento temporal do coeficiente beta da CSN antes e após o evento

Fonte: Elaboração dos autores.

Vale salientar que o presente estudo não se propôs a analisar as potenciais variáveis que poderiam afetar o padrão de volatilidade das ações analisadas, bem como os indicadores mercadológicos ou organizacionais que podem ter provocado a mudança de padrão na volatilidade da CSN.

A Figura 4 mostra o comportamento temporal do risco sistemático da Braskem antes e após a ocorrência do evento.
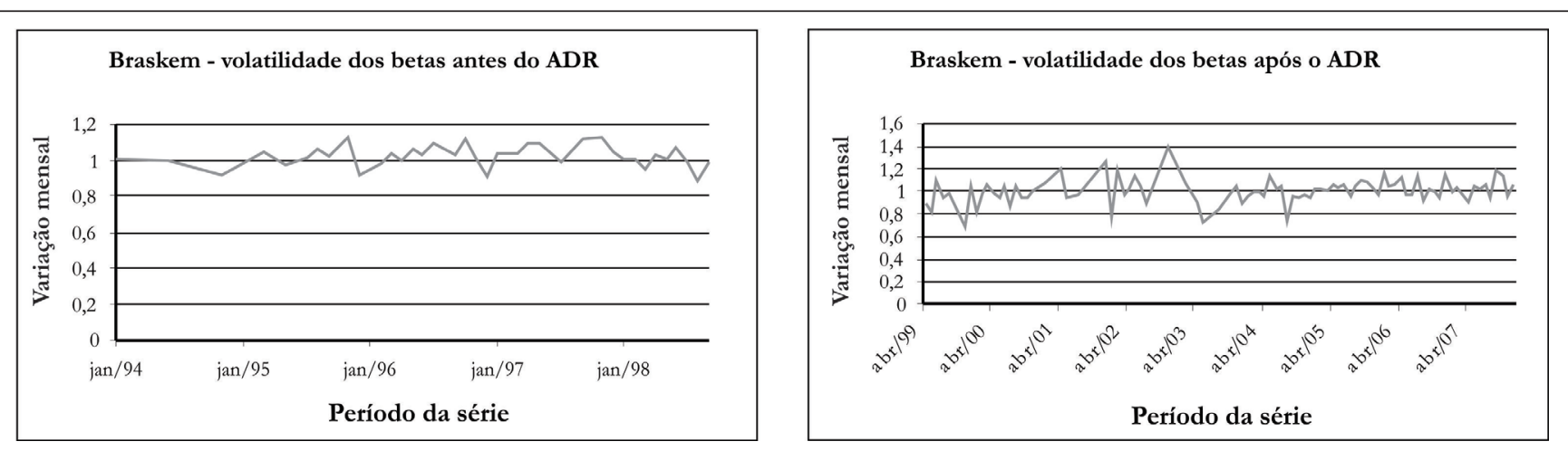

Figura 4 - Comportamento temporal do coeficiente beta da Braskem antes e após o evento

Fonte: Elaboração dos autores. 
Observe na Figura 4 que, em média, existe uma manutenção no padrão das volatilidades das ações da Braskem antes e após a ocorrência do evento, as discrepâncias decorrentes de maiores negociações desse papel não foram consideradas como anormais para o mercado de capitais brasileiro.

A Figura 5 evidencia o comportamento temporal do risco sistemático da ação da empresa Gerdau antes e após a ocorrência do evento.
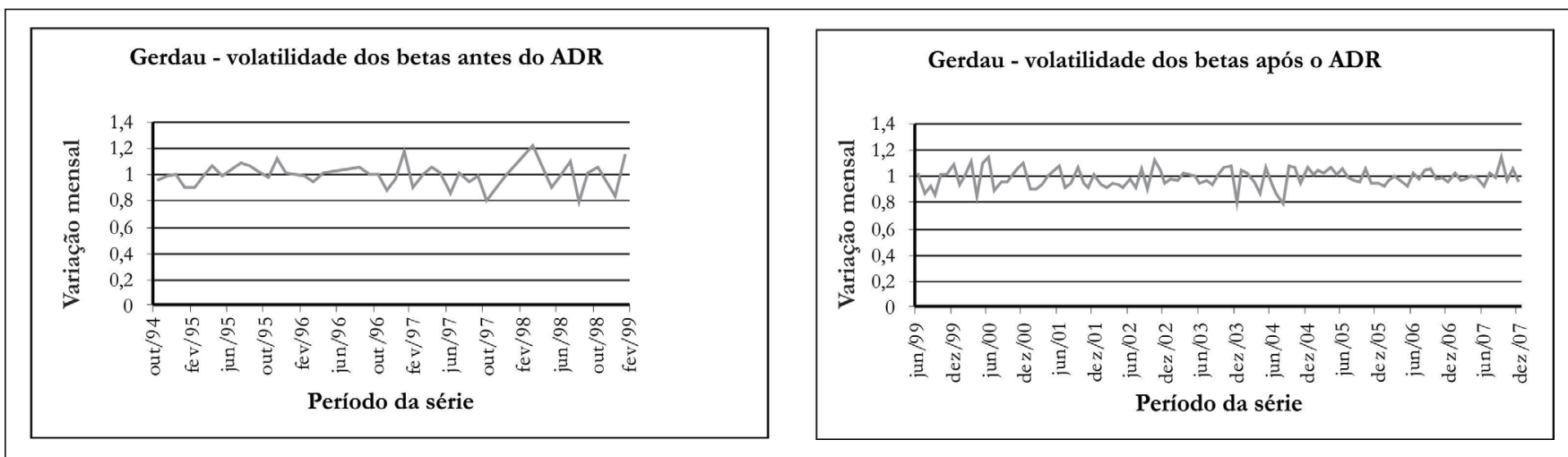

Figura 5 - Comportamento temporal do coeficiente beta da Gerdau antes e após o evento

Fonte: Elaboração dos autores.

Note, por meio da Figura 5, que a volatilidade da ação da Gerdau visualmente se reduz ao longo do tempo. O risco sistemático estimado por meio do coeficiente beta se reduziu em aproximadamente $1,12 \%$, o que é considerado algo natural para os padrões do mercado de capitais brasileiro.

A Figura 6 mostra o comportamento ao longo do tempo do risco sistemático, estimado por meio do coeficiente beta, para a empresa Petrobras.
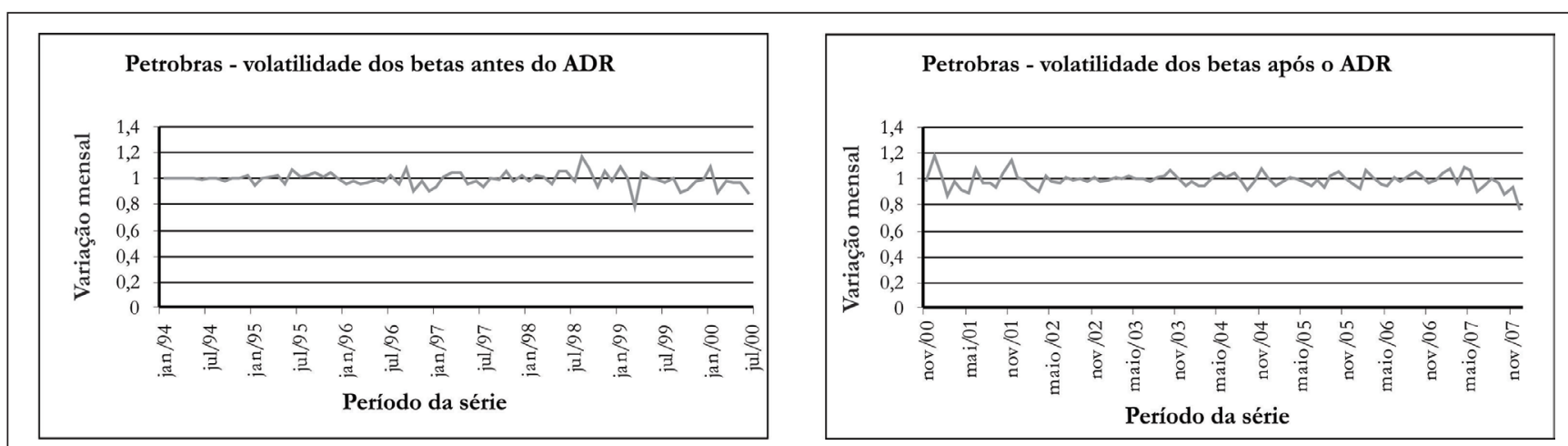

Figura 6 - Comportamento temporal do coeficiente beta da Petrobras antes e após o evento

Fonte: Elaboração dos autores.

Observe na Figura 6, em termos visuais, o comportamento da volatilidade estimada a partir do coeficiente beta para a ação da Petrobras. À medida que se aproxima da janela do evento, a volatilidade desse papel tem uma pequena elevação vindo a se estabilizar posteriormente, de modo a haver um decréscimo de aproximadamente $0,23 \%$. $\mathrm{O}$ resultado descrito anteriormente pode sugerir a maturidade do papel após o início da negociação de ADRs na Bolsa de Valores de Nova Iorque por parte dos investidores que passam a perceber a empresa como um meio seguro de alavancar os seus investimentos.

A Figura 7 mostra o comportamento, ao longo do tempo, do risco sistemático da ação da empresa Vale antes e após a ocorrência do evento. 

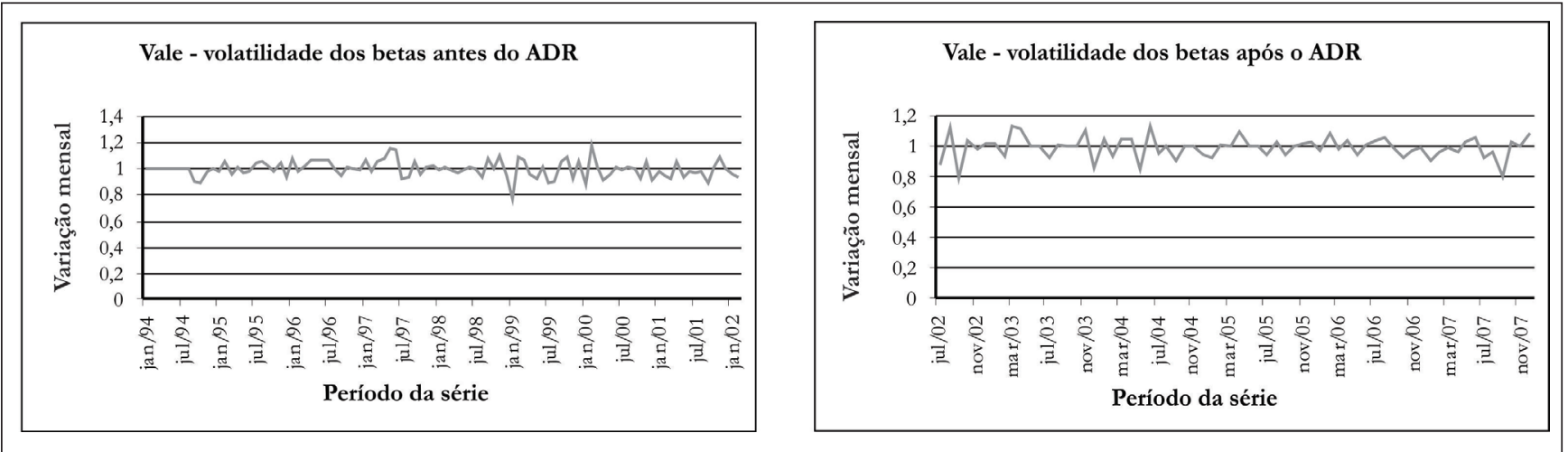

Figura 7 - Comportamento temporal do coeficiente beta da Vale antes e após o evento

Fonte: Elaboração dos autores.

Observe, por meio da Figura 7, que a volatilidade temporal para essa ação também se reduziu após a ocorrência do evento. O decréscimo da taxa de crescimento dessa ação foi de aproximadamente $0,53 \%$.

Apesar das empresas analisadas não terem avaliação do risco de investimentos superiores ao risco soberano do Brasil, exceção da Petrobras e da Vale, todas possuem uma boa reputação nos mercados doméstico e internacional, além de serem vistas pelos investidores como seguras e altamente lucrativas.

Cabe destacar que a volatilidade estimada por meio do risco sistemático é uma das avaliações consideradas como relevantes para quem atua no mercado de ações. Apesar de, em certo sentido, oferecer uma medida da velocidade em termos de negociação do mercado, o presente estudo de evento não permite inferir sobre os motivos da melhora ou piora na percepção do risco após o lançamento do programa de ADR na NYSE.

Não se buscou analisar as mudanças nos padrões de movimento das cinco empresas que foram objetos do estudo. Buscou-se, sim, entender a reação do mercado doméstico ao lançamento de ADRs. A não existência de diferenças significativas nas volatilidades em quatro das cinco empresas analisadas indica que o evento pode ser indiferente para a tomada de decisão do investidor.

\section{Conclusão}

O presente trabalho buscou analisar o efeito do lançamento de um programa de ADR na Bolsa de valores de Nova Iorque na volatilidade dos preços das ações na BM\&FBovespa. O pressuposto inicial considerou a possibilidade de haver melhora na percepção do risco no mercado brasileiro das empresas com ADRs na Bolsa de Nova Iorque. Exceção feita para a empresa CSN, os resultados originados pelos testes de hipóteses para comparação entre médias dos betas antes e após o lançamento do ADR evidenciam não haver mudança estatisticamente significativas no padrão das volatilidades antes e após o lançamento do ADR. Constatou-se, ainda, que no caso da ação da empresa CSN houve elevação considerada significativa estatisticamente na volatilidade após o lançamento do ADR. O trabalho não se propôs a analisar as razões pelas quais não se verificaram mudanças significativas nos preços das ações na BM\&FBovespa.

Nas empresas analisadas, exceção feita para a CSN, os valores encontrados na estatística t-student foram menores que os valores da estatística t-student crítico unicaudal, presumindo-se variâncias equivalentes e com um nível de confiança de 95\%, indicando não haver diferenças estatisticamente significativas entre os betas médios antes e após o lançamento dos ADRs. Dessa forma, foi possível aceitar a hipótese nula de igualdade entre os riscos sistemáticos, estimada por meio dos coeficientes beta médios, no período considerado, para as empresas Braskem, Gerdau, Petrobras e Vale. Contrariamente, os resultados levaram à rejeição da hipótese nula para a empresa CSN.

O fenômeno observado neste trabalho não está suportado por pesquisas anteriores ou corroboram resultados de outros pesquisadores, o que sugere a necessidade de ampliação do estudo para a obtenção de resultados mais consistentes. Estudos 
considerando a inclusão de novas empresas e suas comparações por setores de atuação ou países, por exemplo, são sugeridos como promissores e possíveis de contribuição para a validação dos resultados encontrados neste trabalho. Acredita-se, também, que a análise das razões da manutenção dos padrões de volatilidade ou dos indicadores responsáveis por mudanças na volatilidade poderá oferecer importante contribuição para a compreensão do fenômeno objeto do presente estudo. Na análise dos dados não foram considerados os outliers e sua possível influência nos resultados. Para oferecer uma melhor análise e refinar os resultados, um estudo futuro deverá incluir uma análise de comparação entre as medianas e não somente entre as médias. Dessa forma, o efeito dos outliers na análise dos resultados poderá ser bastante reduzido.

\section{Referências}

ANDREZZO, A. F.; LIMA, I. S. Mercado financeiro: aspectos históricos e conceituais. 4. ed. São Paulo: Thomson Learning, 2009.

BOTOSAN, C. A. Evidence that greater disclosure lowers the cost of equity capital. The Bank of America Journal of Applied Corporate Finance, New York, v. 12, n. 4, p. 60-69, 2000.

BRIGHAM, E.; WESTOM, F. J. Fundamentos da administração financeira. 10. ed. São Paulo: Makron Books, 2000.

BROWN, S. J.; WARNER, J. B. Measuring security price performance. Journal of Financial Economics, Amsterdam, v. 8, n. 3, p. 205-258, 1980.

BRUNI, A. L. Globalização financeira, eficiência informacional e custo de capital: uma análise das emissões de ADRs brasileiros no período 1992-2001. 2002. 250 f. Tese (Doutorado em Administração) Faculdade de Economia, Administração e Contabilidade da Universidade de São Paulo, São Paulo, 2002.

CAMARGOS, M. A.;BARBOSA, F. V.Estudos de evento: teoria e operacionalização. Caderno de Pesquisas e Administração, São Paulo, v. 10, n. 3, p. 1-20, 2003.

CAMPBELL, J. Y.; LO, A.W.; MACKINLAY, A. C. The econometrics of financial markets. 2. ed. New Jersey: Princeton University Press, 1997.
DAMODARAN, A. Investment philosophies: successful investment philosophies and the greatest investors who made than work. 2. ed. Hoboken, NJ: John Wiley \& Sons, 2003.

DOLLEY, J. C. Characteristics and procedure of common stock split-ups. Harvard Business Review, v. 11, n. 4, p. 316-326, 1933.

FREUND, J. E; SIMON, G. A. Estatística aplicada à economia, administração e contabilidade. 2. ed. Porto Alegre: Bookman, 2000.

GIL, A. C. Como elaborar projetos de pesquisa. 4. ed. São Paulo: Atlas, 2002.

GIL, A. C. Métodos e técnicas de pesquisa social. 2. ed. São Paulo: Atlas, 2007.

HAIL, L. The impact of voluntary corporate disclosures on the ex-ante cost of capital for Swiss firms. The European Accounting Review, v. 11, n. 4, p. 741-773, 2002.

HAIR, Jr. J. F. et al. Fundamentos de métodos de pesquisa em administração. 2. ed. Porto Alegre: Bookman, 2005.

HAUGEN, R. A.; TALMOR, E.; TOROUS, W. N. The effect of volatility changes on the level of stock prices and subsequent expected returns. Journal of Finance, New York, v. 46, n. 11, p. 985-1007, 1991.

JUNG, C. F. Metodologia para pesquisa \& desenvolvimento: aplicada a novas tecnologias, produtos e processos. 2. ed. Rio de Janeiro: Axcel Books do Brasil, 2004.

KIN, M.; SZAKMARY, A. C.; MATHUR, I. Price transmission dynamics between ADRs and their underlying foreign securities. Journal of Banking and Finance, New York, v. 24, p. 1359-1382, 2000.

LAPPONI, J. C. Estatística usando Excel 5 e 7. 2. ed. São Paulo: Lapponi, 1997.

LIMA, G. A.S.F.de. Governança corporativa e hipótese de mercado eficiente: o estudo da intenção de emissão de American Depositary Receipts (ADRs) com a utilização de estudos de evento. 2005. 250 f. Dissertação (Mestrado em Ciências Contábeis) - Faculdade de Economia, Administração e Contabilidade da Universidade de São Paulo, São Paulo, 2005.

MACKINLAY, A. C. Event studies in economics and finance. Journal of Economic Literature, Nashville, v. 35, n. 1, p. 13-39, 1997. 
MATSUMOTO, A. S. A emissão de 'ADRs-American Depositary Receipts' pelas empresas da América do Sul e a teoria de mercado eficiente. 1995. 250 f. Tese (Doutorado em Administração de Empresas) - Escola de Administração de Empresas de São Paulo, São Paulo, 1995.

PINDYCK, R. S.; RUBINFELD, D. L. Econometric models and economic forecasts. 3. ed. New York: McGraw-Hill, 1991.

SÁ, G. T. de. Administração de investimentos: teoria de carteiras e gerenciamento do risco. 2. ed. Rio de Janeiro: Qualitymark, 1999.

SOARES, R. O.; ROSTAGNO, L. M.; SOARES, K. T. C. Estudo de evento: o método e as formas de cálculo do retorno anormal. In: ENCONTRO NACIONAL ASSOCIAÇÃONACIONALDE PÓS-GRADUAÇÃO E PESQUISA EM ADMINISTRAÇÃO, 26., 2002, Salvador. Anais... Salvador: ANPAD, 2002. p. 14.

Recebido: 10/08/2010

Received: 08/10/2010

Aprovado: 20/08/2010

Approved: 08/20/2010 